\title{
Adaptability and Productive Qualities of Imported Beef Cattle Under the Conditions of the Northern Region of Kazakhstan
}

\author{
Nurlybai Zhigerbaevich Kazhgaliyev ${ }^{1}$, Saukymbek Kauysovich Shauyenov ${ }^{1}$, \\ Nurbergen Omarkozhauly ${ }^{1}$, Kymbat Hamitovna Shaikenova ${ }^{1}$ \\ and Alexey Ivanovich Shurkin ${ }^{1}$
}

${ }^{1}$ S.Seifullin Kazakh Agro Technical University, Republic of Kazakhstan, 010000, Astana, Pr. Pobedy 62

http://dx.doi.org/10.13005/bbra/2065

(Received: 14 December 2015; accepted: 08 February 2016)

\begin{abstract}
This article examines the basic acclimatization criteria of the beef cattle imported breeds of Hereford, Aberdeen Angus and Aubrac for the productive qualities and the ways of strengthening them in the conditions of Northern Kazakhstan. According to the research results, animals of the Aberdeen-Angus breed showed the highest relative growth rate in the conditions of Northern Kazakhstan. It is followed by the Hereford breed, which exceeds its Aubrac peers by $19.2 \%$ at the beginning of the growing period and by $6.1 \%$ - at the end of the period. Bulls of the Aubrac breed are on the third place according to the relative growth rate. As follows from the study measurements of experimental animals, bulls of the Aubrac breed surpassed their peers of other species by all studied measurements. In comparison with the Hereford, Aberdeen-Angus bulls were somewhat behind the development of body measurements; this does not contradict the known data on the compact physique of this breed. Fattening of Hereford bulls was characterized by the highest profitability under identical conditions (15.3\%), whereas the Aubrac breed under the farm conditions was characterized by the lowest rate of return $(8.9 \%)$. The Aberdeen-Angus bulls occupy an intermediate position (13.4\%). Thus, when creating the beef cattle breeding industry under the conditions of Northern Kazakhstan, it is the most appropriate to use animals of the Hereford and Aberdeen Angus breeds, which adjust well to local conditions.
\end{abstract}

Keywords: breed, beef cattle industry, adaptation, imported animals, meat productivity, growth and development of bull-calves, clinical and physiological, morphological and biochemical parameters.

The task of modern animal husbandry is to not only stabilize, but also increase the production of organic meat, especially beef, due to the increasing demand for high quality food.

The achieved volumes of beef production in Kazakhstan do not currently provide for the needs of the population.

Currently, an urgent need has appeared to open new directions of research related to the current problem of production and sales of

\footnotetext{
* To whom all correspondence should be addressed.
}

agricultural products harmless to human and animal health. This task should be solved at the account of the intensification of cattle production due to the introduction of advanced technologies, fuller use of the genetic potential of meat productivity of farmed livestock, rational management of own feed production, in particular, natural pastures and hayfields with optimal consumption of concentrated feed. Since the area of Northern Kazakhstan is the Schuchinsk-Borovoy resort zone, where a lot of health resorts, rest homes and facilities are concentrated, the need to consider the quality of products more strictly appears that 
determines the direction and the relevance of research on the production of ecologically safe young beef.

From the history of acclimatization of animals to new environmental breeding conditions, it is known that imported animals can successfully live and reproduce, however, they can lose their distinctive qualities of productive and biological features, for which they have been imported. Therefore, the importance of the project is due to the need to develop scientific acclimatization bases of imported livestock in order to obtain the best possible results in the implementation of high genetic productivity potential of animals of the Aberdeen Angus breed in the conditions of Northern Kazakhstan. This will give the opportunity to have a highly productive herd of animals of the Aberdeen Angus and Aubrac breeds well-adapted to the feed, technological and weather conditions in the Akmola and Kostanai regions.

According to the authors, earlier domestic cattle breeds were improved by using the best world's genetic resources, via the import of bulls or the use of their semen, which delayed the creation of highly productive breeds and types for many years. Now, the breeding stock is also imported that allows keeping pure breeding; this circumstance is a new stage in the creation of highly productive herds of cows and is the reason for the novelty and relevance of the articles ${ }^{12}$.

Proceedings of the previous research showed that the information about the acclimatization of beef cattle imported breeds in Kazakhstan is fragmentary, not systematic; the basic criteria of acclimatization are not defined, there is no general theory of acclimatization in relation to feed, process, weathering adaptation factors. None of the imported cattle breeds is evaluated for heat and cold resistance; however, high ambient temperature is the main destabilizing factor of acclimatization. After all, it is the high temperature that has an extremely negative impact on meat and milk productivity, maintenance of homeostasis and genetically determined productivity and reproduction. Minimum parameters of productivity and reproductive qualities are not determined by the breeds in new climatic conditions with the harsh continental climate of various natural zones of Northern Kazakhstan, where cattle breeds are imported and will be imported ${ }^{3-5}$.
Many authors believe that imported animals might be poorly suited to the intensive use due to the relative lack of movement, deprivation of pastures and green forage in the winter period, a high concentration of livestock, as well as the fact that large groups are kept in a limited area and frequently, inadequate feeding space, a high level of mechanization, increased acoustic background. Therefore, it is necessary to closely monitor the health of animals, since only a healthy body has the ability "to balance itself" in this environment, to resist it, to adapt to the new mode of life $\mathrm{e}^{5-8}$.

To date, the state and adaptation of these animals to new climatic conditions are quite good; therefore it is necessary to develop the technology for the better adaptation of animals to the conditions of Nrthern Kazakhstan.

The production of quality beef is impossible without identifying the abilities of highly productive breeding cattle of the Aberdeen Angus breed to adapt to the environmental conditions of Northern Kazakhstan and finding ways to strengthen these abilities.

Thus, one of the major problems of the agricultural sector of the Republic of Kazakhstan is to meet the needs of population in food, particularly high-quality beef; the solution to this problem predetermines the need for the development of beef cattle at the account of both the growth of beef cattle population and increase in its productivity. The increase in the number of beef cattle is carried out using internal resources, expanded reproduction of herds of farmed breeds, as well as through imports, in particular, the Aberdeen Angus and Aubrac breeds. At the same time, maintenance of the high productivity of animals capable of producing high-quality meat products must be provided with the optimized conditions of keeping and feeding, which is especially important with respect to the imported animals, which undergo acclimatization and adaptation to new environmental conditions. In this regard, the focus of the project on the increase in the efficiency potential of beef cattle through the use of effective methods and breeding techniques, creation of new genotypes corresponding to modern requirements together with the study on adaptation and acclimatization of imported beef cattle, feeding, technological and 
biotechnological developments, is relevant and inseparably linked with the implementation of the nation-wide task.

Studying the adaptation of newly imported animals to feed and climatic conditions of detention and economically useful qualities of their offspring in the new environmental conditions is an important task.

\section{Methods}

Scientific and economic experiments on the adaptive qualities of animals imported into the farms of the Akmola region in 2013-2015.

The genetic value of cattle - the method for estimating the breeding value of EPD (expected progeny difference - the expected productivity forecast) has been used. Assessment of the exterior and the constitution - visually, young cattle - on a 5-point scale, adult animals - on a 100-point scale (exterior), the constitution of animals - by the techniques of Y.Ruban, I.Dyurst, Kuleshov-Ivanov. Assessment of growth and development via the comparison with the requirements of standards. Evaluation of the milk producing ability of cows according to the live weight of calves during weaning when they are 6 months old. Evaluation of meat qualities by taking into account the obtained results according to the control slaughter data. Accounting for the feeding costs was carried out through the daily control feeding for two subsequent days by the method of V. Nedavi. Biochemical blood parameters were determined by conventional methods: total protein refractometrically, carotene - by the express electrical colorimetric method, calcium - by the trilonometric method with murexide, inorganic phosphorus, vitamins - by the photo electrical colorimetric method, reserve alkalinity - by the modified diffusion method. The main digital material obtained in the course of research was processed by the method of variation statistics according to Plohinsky N.A.; the reliability was checked by the Student's method using the SPSS application package for Windows.

\section{RESULTSAND DISCUSSION}

In Kazakhstan a large number of cattle is imported from the United States, France, Canada, Australia and other countries: about 36 thousand head of beef cattle, among which 12,429 head of the Aberdeen Angus cattle is registered in the Akmola region and 524 head of the Aubrac breed of different ages. The Aberdeen-Angus breed is characterized not only by well-pronounced forms of meat (slaughter yield - 60-63\%), but also by good acclimatization to different environmental conditions. When crossed with other breeds they greatly pass precocity and meat qualities [9-10].

Aubrac is a breed of cattle that was bred for the first time in the central part of France, and since that time it is the most common meat breed in that region. An important feature of this breed is that it is undemading to the harsh climatic conditions, which makes it possible to breed it in remote, cold regions. The characteristic features of the breed are also endurance, ability to make long passages and digest any food. At birth, the calf weighs from 35 to $40 \mathrm{~kg}$. Daily weight gain on average amounts to $1100-1300 \mathrm{~g}$. Live weight of the bull varies from 850 to $950 \mathrm{~kg}$, weight of the cow is approximately $600 \mathrm{~kg}$, while the slaughter yield is about $63 \%$.

Animals of the Aubrac breed were first brought to Kazakhstan from France in 2011 to the farms of the Akmola region and in 2012-2033 to the Northern Kazahstan area where they showed good adaptation and productive qualities. Currently, the possibility of the wider use of this breed in our country is studied.

We have studied the adaptation of imported cattle of the Hereford, Aberdeen Angus and Aubrac breeds to new feed and climatic conditions of husbandry and determined the economically useful qualities of their offspring in the new conditions of the Akmola region, LLP "AKA", LLP "Semyonovka-AE" and LLP "Novorybinsky and K".

Growth and development features of experimental animals. One of the most important parameters that characterize meat productivity of animals is their live weight and average daily gain over a certain period. In the study of the dynamics of the live weight of experimental calves during the period from birth to 15 months, we found that at birth the Hereford calves had an average live weight of $29.2 \pm 0.3 \mathrm{~kg}$, which is more than the one of the Aberdeen-Angus calves of the same age (24.8 $\pm 0.4 \mathrm{~kg}$ ) by $22.5 \%$ (Table 1 ).

The highest live weight at birth was noted in the animals of the Aubrac breed $-30.7 \pm$ 
$0.81 \mathrm{~kg}$, which is higher than the Hereford calves by $32 \%$ and the Aberdeen Angus calves - by $47 \%$. The same trend was observed during the whole fattening period. At the end of the growing period, the Aubrac calves also had the highest live weight $-435.3 \pm 3.16 \mathrm{~kg}$, which is $13.8 \%$ more than the weight of the Hereford calves $(415.8 \pm 5.7 \mathrm{~kg})$ and 25.9\% more than the Aberdeen Angus (394.7 \pm 3.6 $\mathrm{kg})$. As follows from the data above, all the experimental groups differed from the Hereford by live weight with a high degree of reliability ( $\mathrm{R} \mathrm{d}$ " 0.001): Aberdeen Angus - downwards, and Aubrac - upwards.

Thus, in general the measurement results showed the typical dynamics of the body constitution of animals belonging to different breeds.
Studying the constitution indices of young cattle showed the ambiguity at different ages.

By the age of 15 months, bull-calves of the Aubrac breed were more stretched than their peers, they had a bigger chest index, which indicates the good development of the ribcage, but a smaller blockiness index than the Aberdeen Angus. Boniness indices differed little by breeds; this indicates a similar fortress of their skeleton.

Clinical and physiological indices of imported animals. An important parameter of the life activity of animals in case of a move to another habitat is a respiratory rate, heart rate and body temperature, as they are the parameters of the relative rate of vital functions.

We separately studied these

Table 1. Live weight of calves, $\mathrm{kg}$

\begin{tabular}{|c|c|c|c|c|c|}
\hline \multirow{2}{*}{$\begin{array}{l}\text { Biometrical } \\
\text { parameters }\end{array}$} & \multicolumn{5}{|c|}{ Live weight at an age of, months } \\
\hline & at birth & 3 & 6 & 8 & 15 \\
\hline Hereford breed, $\mathrm{n}=12$ & & & & & \\
\hline $\begin{array}{l}\mathrm{X} \pm \mathrm{Sx} \\
\text { Aberdeen Angus breed, } \mathrm{n}=12\end{array}$ & $29.2 \pm 0.3$ & $124.2 \pm 2.4$ & $205.7 \pm 2.3$ & $244.9 \pm 2.0$ & $323.5 \pm 2.3415 .8 \pm 5.7$ \\
\hline $\begin{array}{l}\mathrm{X} \pm \mathrm{Sx} \\
\text { Aubrac breed, } \mathrm{n}=12\end{array}$ & $24.8 \pm 0.4$ & $114 \pm 1.4$ & $189.1 \pm 2.5$ & $236.5 \pm 1.2$ & $308.2 \pm 3.1394 .7 \pm 3.6$ \\
\hline $\mathrm{X} \pm \mathrm{Sx}$ & $30.7 \pm 0.5$ & $142 \pm 1.5$ & $235.1 \pm 2.2$ & $272.3 \pm 3.4$ & $338.7 \pm 3.8435 .3 \pm 3.1$ \\
\hline
\end{tabular}

Table 2. Physiological characteristics of imported heifers in different seasons, $\mathrm{X} \pm \mathrm{Sx}$

\begin{tabular}{lccc}
\hline Parameters & \multicolumn{3}{c}{ Breed } \\
\cline { 2 - 4 } & Hereford & Aberdeen Angus & Aubrac \\
\hline Winter & & & \\
Body temperature, ${ }^{\circ} \mathrm{C}$ & $38.7 \pm 0.3$ & $38.6 \pm 0.2$ & $38.4 \pm 0.2$ \\
Heart rate, beats per min & $74.2 \pm 0.3$ & $73.7 \pm 0.3$ & $73.4 \pm 0.4$ \\
Respiratory rate, breaths per minute & $27.5 \pm 0.5$ & $27.3 \pm 0.4$ & $26.8 \pm 0.3$ \\
Spring & & & \\
Body temperature, ${ }^{\circ} \mathrm{C}$ & $38.9 \pm 0.3$ & $38.7 \pm 0.2$ & $38.8 \pm 0.1$ \\
Heart rate, beats per min & $71.7 \pm 0.5$ & $71.6 \pm 0.5$ & $71.3 \pm 0.5$ \\
Respiratory rate, breath per minute & $24.8 \pm 0.4$ & $24.5 \pm 0.4$ & $24.3 \pm 0.3$ \\
Summer & & & \\
Body temperature, ${ }^{\circ} \mathrm{C}$ & $38.5 \pm 0.2$ & $38.6 \pm 0.10$ & $38.4 \pm 0.2$ \\
Heart rate, beats per min & $69.6 \pm 0.3$ & $69.4 \pm 0.3$ & $68.8 \pm 0.4$ \\
Respiratory rate, breath per minute & $26.1 \pm 0.3$ & $26.3 \pm 0.3$ & $25.8 \pm 0.3$ \\
Autumn & & & \\
Body temperature, ${ }^{\circ} \mathrm{C}$ & $39.3 \pm 0.3$ & $38.7 \pm 0.1$ & $38.8 \pm 0.1$ \\
Heart rate, beats per min & $64.8 \pm 0.4$ & $64.7 \pm 0.3$ & $64.3 \pm 0.4$ \\
Respiratory rate, breath per minute & $23.1 \pm 0.3$ & $22.8 \pm 0.3$ & $22.1 \pm 0.3$ \\
\hline
\end{tabular}


characteristics of the imported heifers of the experimental groups in different seasons of the year, as the region of North Kazakhstan is characterized by the relatively high variability of climatic conditions during the year compared with the regions of exporters, as well as the characteristics of the bull-calves at different ages, as there is evidence of the ambiguity of the physiological norm under the adaptation conditions for two or three generations after the importation of animals (Table 2).

On the background of highly reliable interbreed differences ( $\mathrm{P} \mathrm{d}$ 0.05-0.001), we revealed certain dynamics of body temperature in different seasons, which varies by the experimental group from $38.2^{\circ} \mathrm{C}$, for the Aubrac breed heifers in the winter it reaches up to $39.2^{\circ} \mathrm{C}$, the Hereford breed - in the autumn. This parameter varied to a lesser extent for the Aberdeen Angus heifers (fluctuations 38.6 to $38.9^{\circ} \mathrm{C}$ or $0.3^{\circ} \mathrm{C}$ ), whereas their peers the fluctuations in body temperature reached $0.4-0.6^{\circ} \mathrm{C}$ and ranged from 38.5 to $39.2^{\circ} \mathrm{C}$, for the Hereford - from 38.2 to $38.9^{\circ} \mathrm{C}$, for the Aubrac breed animals. However, these fluctuations are within the physiological norm of the breed. All the experimental animals were characterized by a decrease in temperature in the summer $\left(38.4-38.6^{\circ} \mathrm{C}\right)$ and increased temperature in the autumn (38.9$\left.39.2^{\circ} \mathrm{C}\right)$.

Dynamics of the respiration rate turned out to be reverse to the dynamics of body temperature: when the body temperature decreased, the number of respiratory movements increased, and vice versa.

Increase in the frequency of respiratory movements of cattle in the summer in the region, when the ambient temperature often stays at +30 $+33^{\circ} \mathrm{C}$ is physiologically substantiated and can be considered a manifestation of adaptive responses to the climate, in which the systemic elimination of

Table 3. The morphological blood parameters of the calves of different breeds $X \pm S x, n=12$

\begin{tabular}{lccc}
\hline Breed & Erythrocytes, mln/mcl & Leucocytes, thousands/mcl & Haemoglobin, g/l \\
\hline Hereford & $7.62 \pm 0.128$ & $8.70 \pm 0.096$ & $114.62 \pm 0.565$ \\
Aberdeen Angus & $6.81 \pm 0.131$ & $8.64 \pm 0.097$ & $113.28 \pm 0.692$ \\
Aubrac & $6.72 \pm 0.124$ & $8.57 \pm 0.112$ & $112.86 \pm 0.913$ \\
\hline
\end{tabular}

Table 4. The protein composition of blood serum of the experimental animals, $X \pm S x, n=10$

\begin{tabular}{lccc}
\hline Parameter & & Breed & \\
& Hereford & Aberdeen Angus & Aubrac \\
\hline Heifers & & & \\
Total protein, g/l & $83.824 \pm 0.15$ & $83.812 \pm 0.101$ & $82.671 \pm 0.043$ \\
Albumins, g/l & $36.203 \pm 0.185$ & $35.613 \pm 0.009$ & $35.013 \pm 0.013$ \\
Total of globulins, g/l & $48.852 \pm 0.033$ & $48.755 \pm 0.096$ & $47.356 \pm 0.033$ \\
Globulin fractions, g/l & & & \\
$\alpha$ & $10.252 \pm 0.014$ & $10.951 \pm 0.016$ & $10.013 \pm 0.009$ \\
$\beta$ & $10.005 \pm 0.011$ & $10.032 \pm 0.015$ & $9.726 \pm 0.019$ \\
$\gamma$ & $27.956 \pm 0.012$ & $27.813 \pm 0.095$ & $26.615 \pm 0.038$ \\
A/G & $0.736 \pm 0.004$ & $0.718 \pm 0.001$ & $0.735 \pm 0.000$ \\
Calves & & & \\
Total protein, g/l & $78.955 \pm 0.471$ & $75.271 \pm 1.162$ & $72.27 \pm 0.731$ \\
Albumins, g/l & $29.998 \pm 0.519$ & $29.034 \pm 0.565$ & $28.66 \pm 0.803$ \\
Total of globulins, g/l & $48.957 \pm 0.363$ & $46.237 \pm 0.663$ & $43.61 \pm 0.736$ \\
Globulin fractions, g/l & & & \\
$\alpha$ & $12.846 \pm 0.260$ & $11.873 \pm 0.324$ & $11.297 \pm 0.218$ \\
$\beta$ & $12.059 \pm 0.255$ & $11.563 \pm 0.282$ & $10.806 \pm 0.297$ \\
$\gamma$ & $24.052 \pm 0.449$ & $22.801 \pm 0.438$ & $21.507 \pm 0.455$ \\
A/G & $0.613 \pm 0.013$ & $0.628 \pm 0.008$ & $0.661 \pm 0.028$ \\
\hline
\end{tabular}


excess heat in the summer is necessary. Probably the result of this active process is a certain decrease in the body temperature in the summer of $0.1-0.4^{\circ} \mathrm{C}$. At the same time, the temperature decreases in the Aberdeen Angus heifers to a lesser extent (from 38.7 to $38.6^{\circ} \mathrm{C}$ ) in comparison with the peers of other breeds (for the Hereford - from 38.9 to $38.5^{\circ} \mathrm{C}$, for the Aubrac - from 38.8 to $38.4^{\circ} \mathrm{C}$ ), which may be associated with a lower body weight.

The heart activity can be seen as a link in the interconnection "respiration - body temperature". We noted the decrease in heart rate since the winter, when it is required to deliver energy to the peripheral parts of the body with the maximum intensity - (73.2-74.1 beats per min.), till the autumn when the animals are experiencing the most comfortable state (64.1-64.7 beats per min). The picture of the seasonal dynamics of cardiac activity is similar for all the breeds, taking into account the fact that the Aubrac heifers showed a lower heart rate at all times of the year (73.2-64.1 beats per min vs. 73.8-64.6 beats per min of the
Aberdeen Angus animals and 74.1-64.7 beats per min of the Hereford).

Hence, we can assume that it is better to import the calves of meat breeds in late summer early autumn, after the drop in daily temperature, when the body of imported animals will not be subjected to the additional stress factors of climatic nature, complicating the acclimatization and adaptation of imported animals.

For the offspring of imported heifers experimental bull calves, we identified a decrease in the examined clinical and physiological parameters at the age of 3 to 15 months, which is an age feature of cattle and it is within the physiological norm. This fact indicates the absence of overstrain in the organism as a result of adaptive processes.

The morphological and biochemical blood parameters of imported animals. In case of a new habitat for animals, quantitative changes in the composition and properties of the blood are observed that are indicative of the reactivity of the

Table 5. The results of the control slaughter of the calves at the age of 15 months, $X \pm S x, n=9$

\begin{tabular}{lllllll}
\hline Parameters & Hereford & $\mathrm{C}_{\mathrm{v}}$ & Aberdeen Angus & $\mathrm{C}_{\mathrm{v}}$ & Aubrac & $\mathrm{C}_{\mathrm{v}}$ \\
\hline Preslaughter live weight, $\mathrm{kg}$ & $415.8 \pm 5.7$ & 2.6 & $394.7 \pm 3.6$ & 5.3 & $435.3 \pm 3.1$ & 2.7 \\
Slaughter weight, kg & $253.63 \pm 4.02$ & & $243.1 \pm 4.1$ & & $284.63 \pm 3.0$ & \\
Slaughter yield, \% & 61.0 & - & 61.6 & - & $64.6-$ & \\
Slaughter weight of a carcass, kg & $231.6 \pm 4.4$ & 3.8 & $221.4 \pm 6.02$ & 5.7 & $269.4 \pm 6.22$ & 4.2 \\
Carcass yield, \% & 55.7 & & 56.1 & & $61.9-$ & \\
Weight of the internal fat tissue, kg & $22.03 \pm 0.84$ & 3.7 & $21.7 \pm 1.02$ & 7.9 & $15.23 \pm 0.89$ & 6.6 \\
Yield of the internal fat tissue, \% & 5.3 & - & 5.5 & - & 3.5 & - \\
Category of beef & 2 & & 2 & & 2 & \\
Weight of the I category subproducts, kg & $59.45 \pm 1.44$ & 6.5 & $61.17 \pm 0.55$ & 8.6 & $57.72 \pm 2.02$ & 9.2 \\
Yield of the I category subproducts, \% & 14.3 & - & 15.5 & - & $13.5-$ & \\
Weight of skin, kg & $41.5 \pm 0.81$ & 43.8 & $35.91 \pm 1.0$ & 5.5 & $42.2 \pm 0.84$ & 4.0 \\
Yield of skin, \% & 10.0 & & 9.1 & & 9.7 & \\
\hline
\end{tabular}

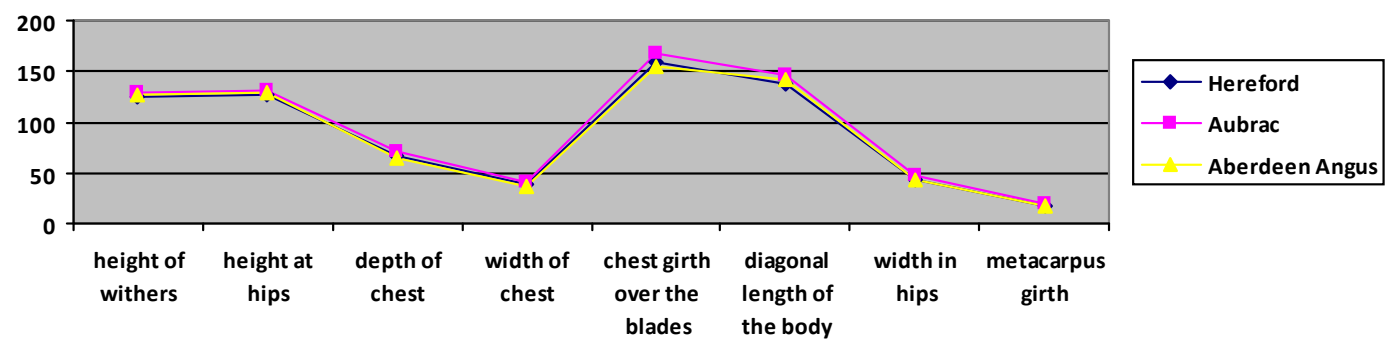

Fig. 1. The differences in size between the animals of different experimental groups compared to the Hereford breed 
body and characterize its natural resistance.

It should be noted that interbreed haematological differences are more pronounced for the imported heifers than their offspring calves, with reliable differences. This may be due to the fact that processes of adaptation and acclimatization are harder and tenser for heifers than bulls. Due to the high energy of growth, a high level of assimilation of fodder, bulls tolerate an acclimatization period easier (Tables 3, 4).

This fact demonstrates the need to correct the system of feeding and housing of heifers in the adaptation period, taking into account the increase in their resilience to adverse factors, increase in their preservation and provision of high heath parameters that will have a favourable effect on their subsequent productive use.

Differences in the amount of erythrocytes in the calves' blood in the international perspective are highly reliable (P d" 0.01) with a higher concentration of erythrocytes in blood (from 6.63 to $7.12 \mathrm{mcl}$ ) compared to the heifers; this indicates higher levels of metabolic processes. Given this fact, higher energy growth of calves is quite understandable, which means the higher feed efficiency compared to the heifers.

Reserve alkalinity of the blood of experimental animals is at the lower limit of the norm (47.21-50.15\%vol. of $\mathrm{CO}_{2}$ with the norm of $52-85 \%)$. This indicates certain strains in animals' bodies in the conditions of Northern Kazakhstan.

The number of leukocytes of the Hereford calves (8.80 thousands/mcl) was higher than that of their peers (8.48-8.54 thousands $/ \mathrm{mcl}$ with $\mathrm{td}=$ 1.8 ... 1.92); this indicates that the Hereford have increased resistance to adverse conditions and gives us the right to consider them more promising in terms of the way the adaptation process goes.

Reproduction parameters of imported livestock. For all the experimental groups, the yield of calves is more than $90 \%$ per 100 cows, which indicates the high quality of imported livestock, as well as high qualification of the personnel.

The Aberdeen Angus animals are of particular interest, calving of these animals occurs easily and without human intervention. $7 \%$ of assisted deliveries and $2 \%$ of caesarean sections are registered for the Aubrac breed; however, this is characteristic of the breed not only due to the big foetus, but also due to the high width parameters of the humeroscapular and hip joints of the foetus.

Preservation of livestock amounted to 9395\%. Both the parameters of calves' yield and the preservation of young cattle are somewhat overstated because of careful attention and operative intervention of the veterinary and zoo technical services of the household when servicing imported animals due to their high cost and the high cost of actions taken for importing.

Meat productivity of bull calves. At the age of 15 , we carried out the control slaughter of experimental calves, 3 head per each group (Table 5)

In general, weight of the Hereford and Aberdeen Angus carcasses differs by $33.2 \mathrm{~kg}$, or 15.87\% (P d 0.001), the difference between the Hereford and Aubrac amounts to $75.6 \mathrm{~kg}$, or $31.19 \%$ at P d $\quad 0 / 001(\mathrm{td}=9.93)$. Per $1 \mathrm{~kg}$ of carcasses of the Hereford there were $94.8 \mathrm{~g}$ of internal fat tissue, Aberdeen Angus - $151.5 \mathrm{~g}$, Aubrac - 55 g, which in combination with the greater live weight confirms the relatively smaller fat content in the Aubrac animals.

The highest profitability is obtained with the Hereford bull calves (15.3\%); the lowest parameter of profitability was established for the Aubrac breed bull calves (8.9\%).

The Aberdeen-Angus calves take up the intermediate position according to the examined parameter (13.4\%). During the assessment of the cost-effectiveness, the realization price of 1 quintal of beef in live weight amounted to 108,000 tenge.

\section{CONCLUSION}

The study established the breed features of live weight formation of experimental animals in the conditions of Northern Kazakhstan that meet their breed characteristics. On the basis of the boniness index it was found that the less massive Aberdeen Angus breed with the metacarpus girth of 17.4-18.6 cm when being in the similar conditions of foothill pastures together with the Aubrac and Hereford breed animals (metacarpus girth of 17.218.4 of the Hereford animals and 18.58-19.2 cm of the Aubrac animals) adapts easier than their peers. Animals of the Aberdeen-Angus breed showed the highest relative growth rate in the conditions of Northern Kazakhstan. It is followed by the 
Hereford breed, which exceeds its Aubrac peers by $19.2 \%$ at the beginning of the growing period and $6.1 \%$ - at the end of the period. Bulls of the Aubrac breed are on the third place according the relative growth rate. Reserve blood alkalinity of the experimental animals is at the lower limit of normal, indicating that animals experience certain strains in the new climatic conditions. The carcasses of the Aberdeen-Angus calves contained more high-grade meat. During the assessment of the quality of beef products of the Aberdeen-Angus breed, produced according to the specifications, we established the improvement of consistency and increased availability of protein to the impact of digestive enzymes compared with the Hereford and Aubrac breeds.

Fattening of Hereford bulls was characterized by the highest profitability under identical conditions (15.3\%), whereas the Aubrac breed under the farm conditions was characterized by the lowest rate of return (8.9\%). The AberdeenAngus bulls occupy an intermediate position (13.4\%). Thus, when creating the beef cattle breeding industry under the conditions of Northern Kazakhstan, it is the most appropriate to use animals of the Hereford and Aberdeen-Angus breeds, which adjust to local conditions well.

\section{REFERENCES}

1. Warzecha, H., Spitzentiere aus Matterkuhherd. Mast-und Schlact leistungverchiedener
Fleischrindgenotypen. Neue Landwirtisch, 2005; 8: 62-63.

2. West-Eberhard, M.J., Developmental Plasticity and Evolution. Oxford: Univ. Press, 2003.

3. Lysenko, L.A., Growth, Development and Haematological Parameters of Cattle of the Aubrac Breed of Different Generations under the Conditions of Northern Kazakhstan. Siberian Bulletin of the Agricultural Science, 2008; 4: 64-70.

4. Rainey, P.B. and M. Travisano, Adaptive Radiation in a Heterogeneous Environment. Nature, 1998; 394: 69-72.

5. Jump, A.S., Running to Stand Still: Adaptation and the Response of Plants to Rapid Climate Change. Ecol. Lett., 2005; 8: 1010-1020.

6. Xie, X., Q. Meng, Z. Cui and L. Ren, Effect of Cattle Breed on Meat Quality, Muscle Fiber Characteristics, Lipid Oxidation and Fatty Acids in China. Asian Australas. J. Anim. Sci., 2012; 25(6): 824-831.

7. Grigorieva, M.G., Cattle Adaptation in Kuban. Animal Husbandry in Russia, 2009; 9: 43-44.

8. Surai, P.F. and V. Fisinin, Selenium in Poultry Breeder Nutrition: An Update. Animal Feed Science and Technology, 2014; 191: 1-15.

9. Grigorieva, M.G., The Exterior Assessment of Beef Cattle Imported into the Krasnodar Region. In Scientific Bases of Increasing the Efficiency of Agricultural Animals: Proceedings of the Anniversary International Scientific and Practical Conference (Part 2), 2009; 18.

10. Mityukov, A., Beef Cattle Breeding is the Basis of High Profits. Chief Animal Technician, 2009; 2: $26-28$. 